Article

\title{
Smartphone-Based Point-of-Care Cholesterol Blood Test Performance Evaluation Compared with a Clinical Diagnostic Laboratory Method
}

\author{
Kyongsik Yun ${ }^{1}{ }^{1}$, Jaekyu Choi ${ }^{1}$, In-Uk Song ${ }^{2, *}$ and Yong-An Chung ${ }^{3, *}$ \\ 1 BBB Inc., Seoul 06194, Korea \\ 2 Department of Neurology, Incheon St. Mary's Hospital, The Catholic University of Korea, \\ Incheon 21431, Korea \\ 3 Department of Radiology, Incheon St. Mary's Hospital, The Catholic University of Korea, \\ Incheon 21431, Korea \\ * Correspondence: siuy70@gmail.com (I.-U.S.); yongan@catholic.ac.kr (Y.-A.C.); Tel.: +82-32-280-5243 (Y.-A.C.)
}

Received: 10 July 2019; Accepted: 14 August 2019; Published: 14 August 2019

check for updates

Featured Application: Faster, more convenient point-of-care cholesterol blood test.

\begin{abstract}
Managing blood cholesterol levels is important for the treatment and prevention of diabetes, cardiovascular disease, and obesity. An easy-to-use, portable cholesterol blood test could accelerate more frequent testing by patients and at-risk populations. We aim to evaluate the performance of smartphone-based point-of-care cholesterol blood tests compared to that of hospital-grade laboratory tests. We used smartphone systems that are already familiar to many people. Because smartphone systems can be carried around everywhere, blood can be measured easily and frequently. We compared the results of cholesterol tests with those of existing clinical diagnostic laboratory methods. We found that smartphone-based point-of-care lipid blood tests were as accurate as hospital-grade laboratory tests $(\mathrm{N}=116, \mathrm{R}>0.97, p<0.001$ for all three cholesterol blood tests, i.e., total cholesterol, high density lipoprotein, and triglyceride). Our system could be useful for those who need to manage blood cholesterol levels to motivate them to track and control their behavior.
\end{abstract}

Keywords: point-of-care; cholesterol; clinical diagnostics; laboratory test

\section{Introduction}

Total cholesterol (TC), high density lipoprotein (HDL), and triglyceride (TG) levels indicate blood lipid levels. Controlling blood lipid levels is known to be at least indirectly associated with the treatment and prevention of various diseases, including diabetes mellitus [1], cardiovascular disease [2], and obesity [3]. It is important to quickly and easily diagnose blood lipid levels using a point-of-care testing (POCT) device to control blood lipid levels more effectively than hospital examinations [4].

By removing barriers to blood testing, patients can check their blood more frequently. This gives them access to temporal changes in their biomarkers, making it easier to monitor and manage their health. One way to remove barriers to testing is to use the familiar smartphone interface [5]. We can take advantage of the sophisticated imaging technology and computing power available in smartphones, which enables more accurate and comprehensive diagnostics. This may improve preventive treatment for chronic metabolic diseases.

The elemark ${ }^{\mathrm{TM}}$ lipid check is a smartphone-based in vitro diagnostic device for rapid self-testing of three lipid markers. This device has functions to store/output the measured value. A whole blood sample that does not require centrifugation is used in the test to shorten the test time. This study examines the accuracy of the elemark ${ }^{\mathrm{TM}}$ lipid tests compared to hospital grade clinical diagnostic 
laboratory methods, which are typically full-menu clinical chemistry analyzers, processing up to 2000 tests per hour with a full menu of assays, ideal for large hospitals. Small hospitals and individual patients need an easy-to-use point-of-care alternative because they cannot afford the size and cost of a full menu analyzer.

\section{Materials and Methods}

The elemark ${ }^{\mathrm{TM}}$ lipid check device was developed in September 2016 as a self-testing cholesterol measuring device. TC, HDL, and TG were measured using elemark ${ }^{\mathrm{TM}}$ compatible cholesterol test strips. The elemark ${ }^{\mathrm{TM}}$ System includes the elemark ${ }^{\mathrm{TM}}$ Analyzer and the SD LipidoCare ${ }^{\mathrm{TM}}$ lipid test strip (Figure 1).

The system is operated on a lithium-ion battery (3000 mAh), providing 2G (850/900/1800/1900), 3G (850/900/1900/2100), 4G (800/850/1700/1800/2100/2600), Wi-Fi (802.11 b/g/n), and Bluetooth (V4.0) connectivity. The dimensions of the device are $159 \mathrm{~mm} \times 81 \mathrm{~mm} \times 9.5 \mathrm{~mm}$, with a 5.5 inch HD display and a weight of $193 \mathrm{~g}$. The system runs on Android ${ }^{\mathrm{TM}} \mathrm{OS}$, an MT6735P processor, and $32 \mathrm{~GB}$ ROM/3 GB RAM memory. The test time duration was $3 \mathrm{~min}$ and a $35 \mathrm{uL}$ blood sample was required. The detection ranges of TC, TG, and HDL were 100-450 mg/dL, 45-650 mg/dL, and 25-95 mg/dL, respectively.

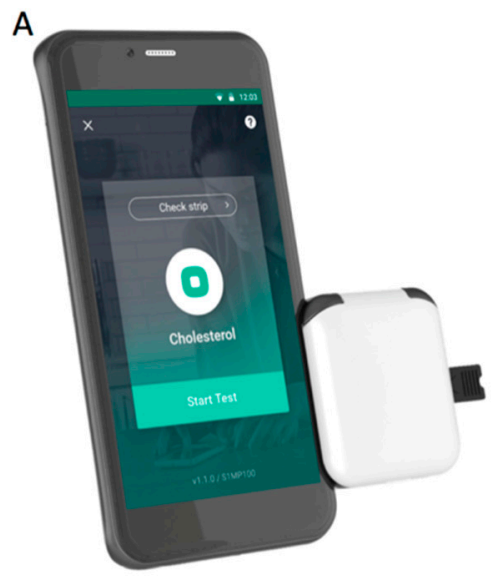

D

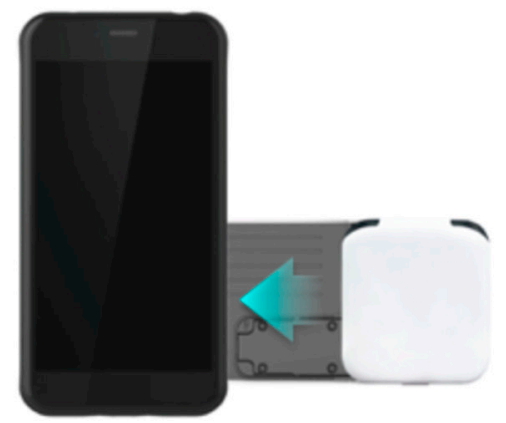

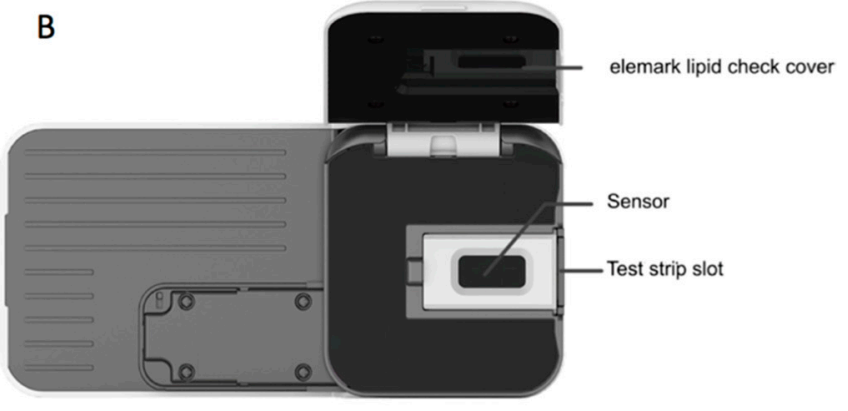

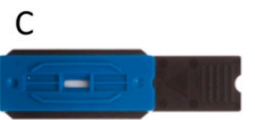

$E$

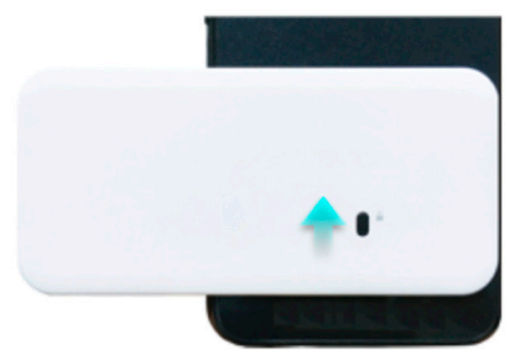

Figure 1. Device components. (A) elemark ${ }^{\mathrm{TM}},(\mathbf{B})$ elemark $^{\mathrm{TM}}$ lipid check, (C) elemark ${ }^{\mathrm{TM}}$ lipid check cholesterol test strip, (D) connection of the elemark ${ }^{\mathrm{TM}}$ lipid check to a compatible mobile device in the shown direction, (E) button is pushed up to lock the elemark ${ }^{\mathrm{TM}}$ lipid check.

This experiment was approved by the Incheon St. Mary's Hospital Institutional Review Board (IRB) in Incheon, South Korea (OC16SISI0139), and complied with the World Medical Association Declaration of Helsinki regarding ethical conduct of research involving human subjects. We followed the experimental procedures described in the normative references for the application of the International Organization for Standardization (ISO) [6,7]. We recruited normal participants (20-80 years of age) from the local community in Incheon, South Korea. All participants were given thorough explanations 
about the experiment and they all gave written informed consent. We anonymized the identity of the sample sources. Because it was a simple blood test, the risk of the sample supplier was minimized. Minimal risk is defined as the degree and severity of harm or discomfort that may arise from studies not greater than the daily life of a healthy person or a routine physical or psychological examination [8].

The test temperature was controlled at $20 \sim 26^{\circ} \mathrm{C}$ during the experiment. The AU5800 Analyzer (Beckman Coulter Inc., IN, USA) was used as the reference device. Total cholesterol (TC), triglyceride (TG), and high-density lipoprotein (HDL) were measured and reported. Low density lipoprotein (LDL) was calculated as TC-HDL-TG/5. LDL was not reported in this evaluation study.

The elemark ${ }^{\mathrm{TM}}$ cholesterol meter was stored at $-30^{\circ} \mathrm{C}$ to $70{ }^{\circ} \mathrm{C}$, with a relative humidity of $90 \%$ or less and an altitude of less than $2000 \mathrm{~m}$. The cholesterol test strips (SD Biosensor LipidCare Lipid Profile Strips) were stored at room temperature between $2{ }^{\circ} \mathrm{C}$ and $32{ }^{\circ} \mathrm{C}$ and were used immediately after the individual pouches were opened.

The venous whole blood in the treated ethylenediaminetetraacetic acid (EDTA) tube was used for elemark ${ }^{\mathrm{TM}}$ and the venous serum blood in the treated EDTA tube was separated from the venous whole blood and used in the reference device (AU5800). We recruited 116 participants for a blood test ( 80 women, 36 men, $70.8 \pm 10.8$ years) (Table 1 ). Samples were tested and analyzed within one day of blood collection. The comparison results between elemark ${ }^{\mathrm{TM}}$ and AU5800 were analyzed. A correlation coefficient was used to evaluate the correlation between the two measurements (Figure 2).
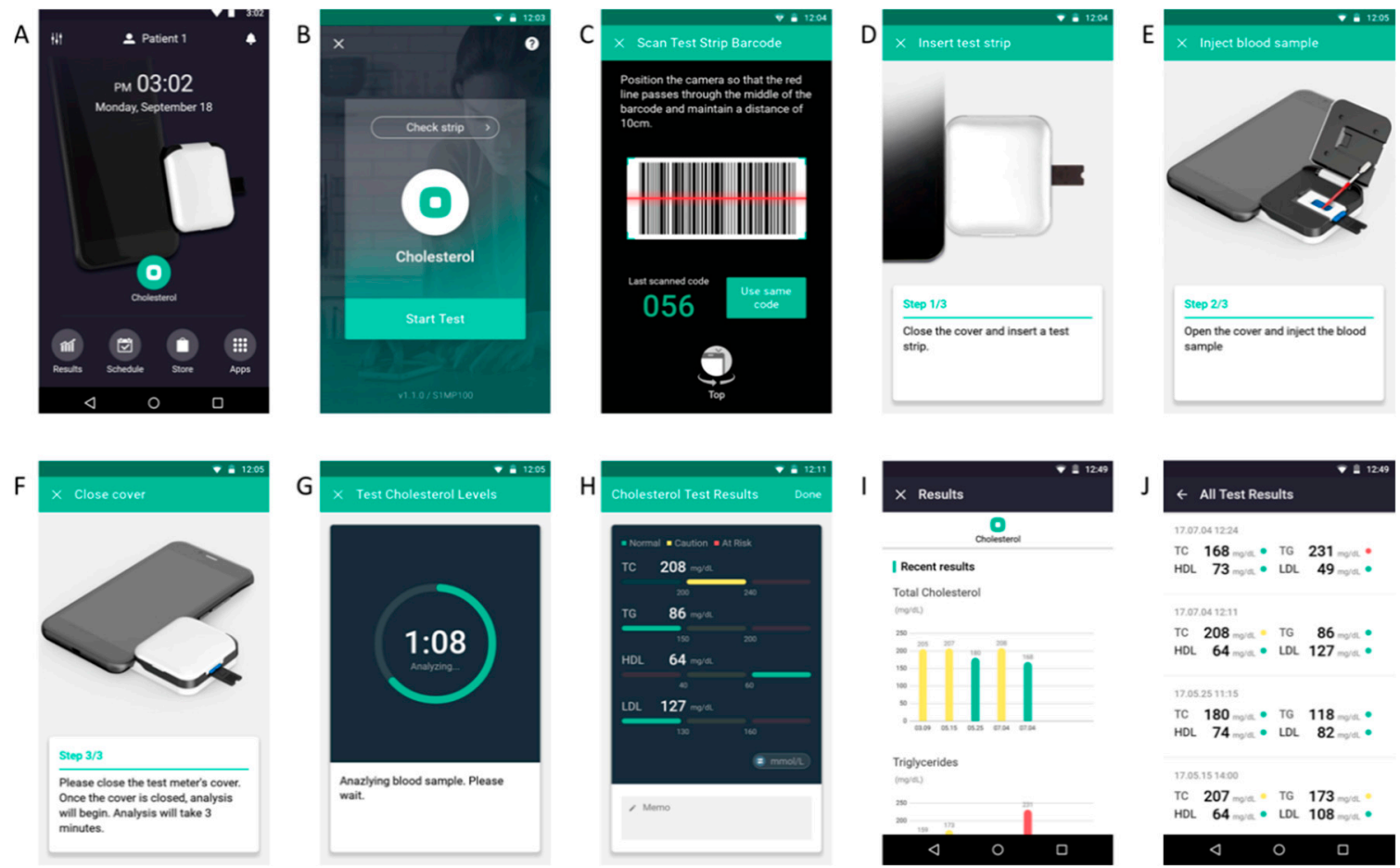

Figure 2. Test procedure. (A) Tap on the cholesterol icon to launch the app. (B) Press the Start Test button. (C) Use the camera of the mobile device to scan the barcode in the strip box. Once the cholesterol test strip is validated, the app automatically goes to the next step. (D) Insert the cholesterol measurement strip into the elemark ${ }^{\mathrm{TM}}$ lipid check as shown. (E) Blood samples are collected using a lancing device. Open the elemark ${ }^{\mathrm{TM}}$ lipid check cover, place the open end of the capillary into the sample area of the cholesterol test strip, and gently squeeze the capillary tube bulb to inject the blood sample. (F) Follow the on-screen instructions to close the cover. (G) Wait three minutes for analysis. (H) When the analysis is finished, the test results are displayed on the screen. (I) The user can check the latest test result graphically. (J) The user can check all test results.

Tukey's fences were used to identify outliers based on interquartile range. The interquartile range is a measure of the statistical variance and is equivalent to the difference between the 75th and 25th 
percentiles. For example, if $Q 1$ and $Q 3$ are the lower and upper quartiles, respectively, anomalies can be defined with any observation outside the range:

$$
[Q 1-k(Q 3-Q 1), Q 3+k(Q 3-Q 1)]
$$

When $k=1.5$, values out of the above range were regarded as outliers $[9,10]$.

Table 1. Sample distribution of total cholesterol (TC), triglyceride (TG), and high-density lipoprotein (HDL) concentrations.

\begin{tabular}{cccc}
\hline TC Concentration (mg/dL) & N & Total & $\%$ \\
\hline Below 200 mg/dL (Normal) & 86 & 116 & 74.1 \\
200 239 mg/dL (Borderline High) & 24 & 116 & 20.7 \\
Above 240 mg/dL (High) & 6 & 116 & 5.2 \\
\hline TG concentration (mg/dL) & $\mathbf{N}$ & Total & $\%$ \\
\hline Below 150 mg/dL (Normal) & 71 & 116 & 61.2 \\
150 199 mg/dL (Borderline High) & 22 & 116 & 19.0 \\
200 499 mg/dL (High) & 22 & 116 & 19.0 \\
Above 500 mg/dL (Very high) & 1 & 116 & 0.9 \\
\hline HDL concentration (mg/dL) & $\mathbf{N}$ & Total & $\%$ \\
\hline Below 40 mg/dL (Low) & 22 & 116 & 19.0 \\
40 59 mg/dL (Normal) & 60 & 116 & 51.7 \\
Above 60 mg/dL (High) & 34 & 116 & 29.3 \\
\hline
\end{tabular}

\section{Results}

We compared the results between the elemark ${ }^{\mathrm{TM}}$ and reference devices (Table 2). Linear regression analysis showed that TC, TG, and HDL had high correlations between the two devices (TC: correlation coefficient $(R)=0.97$, coefficient of determination $\left(R^{2}\right)=0.94, p$-value $=2.25 \times 10^{-73}$; TG: $R=0.99$, $\mathrm{R}^{2}=0.98, p$-value $=1.34 \times 10^{-92} ; \mathrm{HDL}: \mathrm{R}=0.97, \mathrm{R}^{2}=0.93, p$-value $\left.=1.67 \times 10^{-69}\right)($ Figure 3$)$.

Table 2. System accuracy.

\begin{tabular}{|c|c|c|c|c|c|c|c|}
\hline & \multicolumn{3}{|c|}{$<100 \mathrm{mg} / \mathrm{dL}$} & \multicolumn{4}{|c|}{$\geqq 100 \mathrm{mg} / \mathrm{dL}$} \\
\hline & $\begin{array}{l}\text { Within } \\
\pm 5 \mathrm{mg} / \mathrm{dL}\end{array}$ & $\begin{array}{l}\text { Within } \\
\pm 10 \mathrm{mg} / \mathrm{dL}\end{array}$ & $\begin{array}{l}\text { Within } \\
\pm \mathbf{1 5} \mathrm{mg} / \mathrm{dL}\end{array}$ & $\begin{array}{c}\text { Within } \\
\pm 5 \%\end{array}$ & $\begin{array}{c}\text { Within } \\
\pm 10 \%\end{array}$ & $\begin{array}{l}\text { Within } \\
\pm 15 \%\end{array}$ & $\begin{array}{l}\text { Within } \\
\pm 5 \%\end{array}$ \\
\hline \multirow{2}{*}{ TC } & \multirow{2}{*}{\multicolumn{3}{|c|}{ N/A (Device range: 100 450 mg/dL) }} & $87 / 116$ & $112 / 116$ & $115 / 116$ & $116 / 116$ \\
\hline & & & & $75.00 \%$ & $96.60 \%$ & $99.10 \%$ & $100 \%$ \\
\hline \multirow{2}{*}{ TG } & $8 / 24$ & $17 / 24$ & $23 / 24$ & $42 / 92$ & $71 / 92$ & $89 / 92$ & $92 / 92$ \\
\hline & $33.30 \%$ & $70.80 \%$ & $95.80 \%$ & $45.70 \%$ & $77.20 \%$ & $96.70 \%$ & $100 \%$ \\
\hline \multirow{2}{*}{ HDL } & $98 / 116$ & $116 / 116$ & $116 / 116$ & \multirow{2}{*}{\multicolumn{4}{|c|}{ N/A (device range: $25 \sim 95 \mathrm{mg} / \mathrm{dL}$ ) }} \\
\hline & $84.50 \%$ & $100 \%$ & $100 \%$ & & & & \\
\hline
\end{tabular}

The system accuracy results showed that $99.1 \%$ of the TC concentration values at $100 \mathrm{mg} / \mathrm{dL}$ or above were within $\pm 15 \%$ of the reference results, $96.7 \%$ of the TG concentration values at $100 \mathrm{mg} / \mathrm{dL}$ or above were within $\pm 15 \%$ of the reference results, and $100 \%$ of the HDL concentration values less than $100 \mathrm{mg} / \mathrm{dL}$ were within $\pm 10 \mathrm{mg} / \mathrm{dL}$ of the reference results (Table 2). 

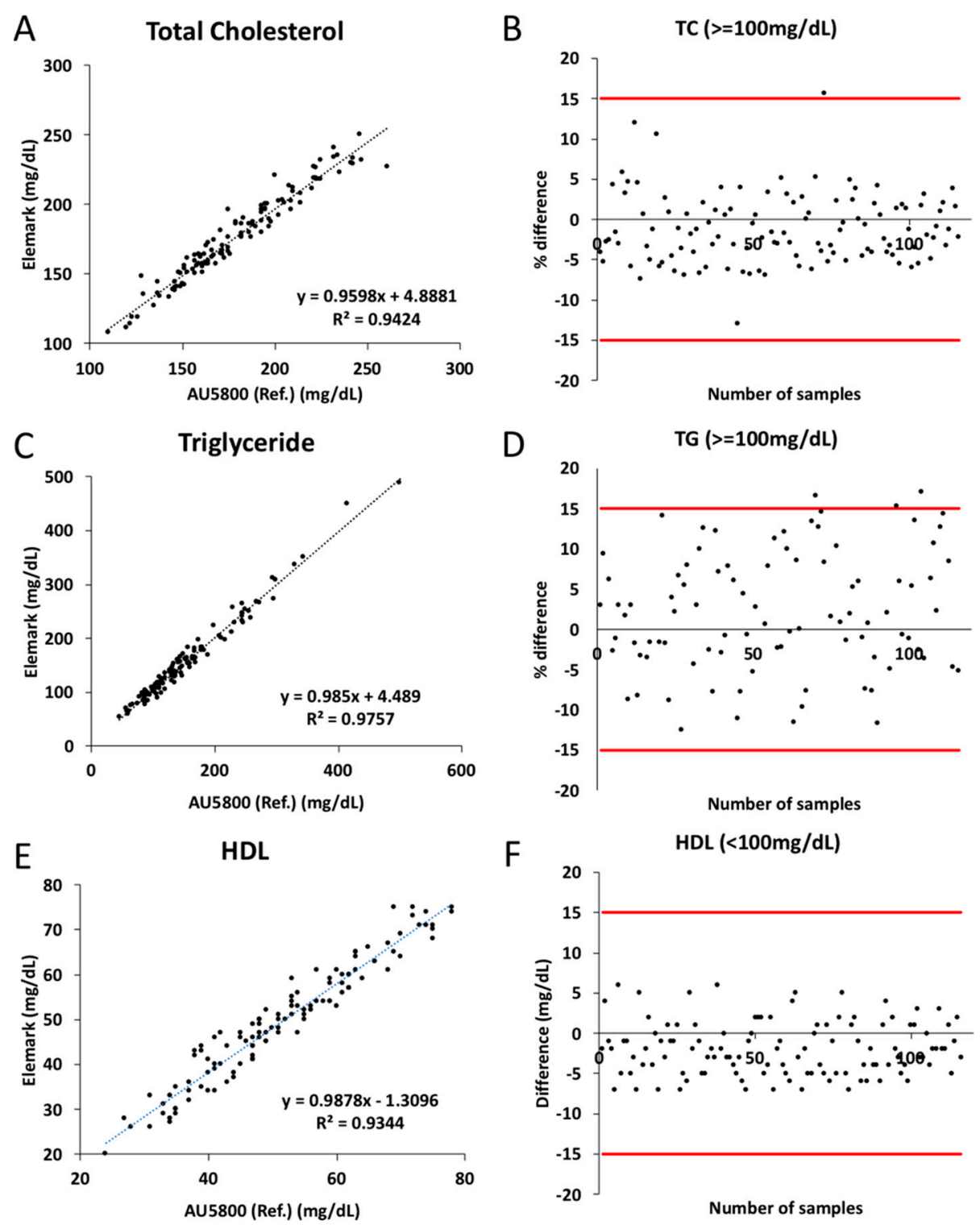

Figure 3. Regression and difference charts between the proposed device (elemark ${ }^{\mathrm{TM}}$ ) and the reference device (AU5800). (A) Total cholesterol (TC) regression chart, (B) percent difference chart with $\pm 15 \%$ accuracy standard, (C) triglyceride (TG) regression chart, (D) percent difference chart with $\pm 15 \%$ accuracy standard, (E) high density lipoprotein (HDL) regression chart, (F) percent difference chart with $\pm 10 \%$ accuracy standard.

\section{Discussion}

We verified the accuracy of elemark ${ }^{\mathrm{TM}}$ by confirming the correlation between the whole blood lipid measurement values of three lipid markers (TC, TG, HDL) from elemark ${ }^{\mathrm{TM}}$ and the serum lipid values of the same three lipid markers from existing automated hospital equipment. elemark ${ }^{\mathrm{TM}}$ satisfied the acceptance criteria for the CE approval; $95 \%$ of the individual blood-testing parameter result fell within $\pm 10 \mathrm{mg} / \mathrm{dL}$ of the appropriate reference result at HDL concentration $<100 \mathrm{mg} / \mathrm{dL}$ and within $\pm 15 \%$ of the reference result at TC and TG concentrations $\geq 100 \mathrm{mg} / \mathrm{dL}$ [11].

We used a smartphone-based, easy-to-use, intuitive user interface (Figure 2) [12,13]. Smartphone-based point-of-care blood tests have several advantages in terms of computation, communication, usability, and cost-effectiveness [14,15]. In addition, data generated from point-of-care devices can be easily shared with caregivers and healthcare professionals, helping to manage chronic disease in patients. Because the device is always connected to the network, data points cannot be lost 
and the generated data can be automatically saved and configured for later analysis. Future machine learning-based analysis will allow us to predict cholesterol levels and calculate a patient's risk of metabolic disease [16,17].

Our study has several limitations. We used venous blood for the elemark ${ }^{\mathrm{TM}}$ test. Capillary whole blood results are known to be different from venous whole blood results [18]. Future studies showing actual use cases should use capillary whole blood. We are also aware that the recruited participants were mainly from the elderly population ( $70.8 \pm 10.8$ years of age). However, we believe that our current study of method comparison results is independent of age distribution. Rather, our results showed that elderly participants at high risk for cardiovascular disease produced accurate cholesterol diagnostics.

Author Contributions: Conceptualization, K.Y., J.C., I.-U.S. and Y.-A.C.; methodology, K.Y.; software, K.Y.; validation, K.Y., I.-U.S. and Y.-A.C.; formal analysis, K.Y.; investigation, K.Y., I.-U.S. and Y.-A.C.; resources, J.C.; data curation, I.-U.S. and Y.-A.C.; writing-original draft preparation, K.Y.; writing—review and editing, K.Y., I.-U.S. and Y.-A.C.; visualization, K.Y.; supervision, I.-U.S. and Y.-A.C.; project administration, J.C.; funding acquisition, J.C.

Funding: This study was funded by BBB Inc.

Acknowledgments: The authors acknowledge Juhee Lee for her technical support.

Conflicts of Interest: K.Y. and J.C. work for BBB Inc.

\section{References}

1. New, M.I.; Roberts, T.N.; Bierman, E.L.; Reader, G.G. The Significance of Blood Lipid Alterations in Diabetes Mellitus. Diabetes 1963, 12, 208-212. [CrossRef] [PubMed]

2. Frantz, I.D.; Dawson, E.A.; Ashman, P.L.; Gatewood, L.C.; Bartsch, G.E.; Kuba, K.; Brewer, E.R. Test of effect of lipid lowering by diet on cardiovascular risk. The Minnesota Coronary Survey. Arterioscler. Thromb. Vasc. Biol. 1989, 9, 129-135.

3. Ravelli, A.; van der Meulen, J.H.P.; Osmond, C.; Barker, D.; Bleker, O. Infant feeding and adult glucose tolerance, lipid profile, blood pressure, and obesity. Arch. Dis. Child. 2000, 82, 248-252. [CrossRef] [PubMed]

4. Pai, N.P.; Vadnais, C.; Denkinger, C.; Engel, N.; Pai, M. Point-of-Care Testing for Infectious Diseases: Diversity, Complexity, and Barriers in Low- And Middle-Income Countries. PLoS Med. 2012, 9, e1001306. [CrossRef] [PubMed]

5. Oncescu, V.; Mancuso, M.; Erickson, D. Cholesterol testing on a smartphone. Lab Chip 2014, 14, 759-763. [CrossRef] [PubMed]

6. Kroll, M.H.; Biswas, B.; Budd, J.R.; Durham, P.; Gorman, R.T.; Gwise, T.E.; Halim, A.; Hatjimihail, A.T.; Hilden, J.; Kyunghee, S. Assessment of the diagnostic accuracy of laboratory tests using receiver operating characteristic curves; approved guideline. Clin. Lab. Stand. Inst. Doc. 2011, 31, 1-45.

7. International Organization for Standardization. In Vitro Diagnostic Test Systems: Requirements for Blood-glucose Monitoring Systems for Self-testing in Managing Diabetes Mellitus; ISO: Geneva, Switzerland, 2003.

8. 45 CFR 46. Available online: https://www.hhs.gov/ohrp/regulations-and-policy/regulations/45-cfr-46/index. html (accessed on 26 March 2018).

9. Hoaglin, D.C.; Iglewicz, B.; Tukey, J.W. Performance of some resistant rules for outlier labeling. J. Am. Stat. Assoc. 1986, 81, 991-999. [CrossRef]

10. Hoaglin, D.C.; John, W. Tukey and data analysis. Stat. Sci. 2003, 18, 311-318.

11. Shephard, M.D.; Mazzachi, B.C.; Shephard, A.K. Comparative performance of two point-of-care analysers for lipid testing. Clin. Lab. 2007, 53, 561-566. [PubMed]

12. Erickson, D.; O’Dell, D.; Jiang, L.; Oncescu, V.; Gumus, A.; Lee, S.; Mancuso, M.; Mehta, S. Smartphone technology can be transformative to the deployment of lab-on-chip diagnostics. Lab Chip 2014, 14, 3159-3164. [CrossRef] [PubMed]

13. Roda, A.; Calabretta, M.M.; Calabria, D.; Caliceti, C.; Cevenini, L.; Lopreside, A.; Zangheri, M. Smartphone-Based Biosensors for Bioanalytics: A Critical Review. In Past, Present and Future Challenges of Biosensors and Bioanalytical Tools in Analytical Chemistry: A Tribute to Professor Marco Mascini, Volume 77; Elsevier Science Ltd.: Oxford, UK, 2017; Chapter 8; p. 237. 
14. Haggerty, L.; Tran, D. Cholesterol point-of-care testing for community pharmacies: A review of the current literature. J. Pharm. Pract. 2017, 30, 451-458. [CrossRef] [PubMed]

15. El-Osta, A.; Woringer, M.; Pizzo, E.; Verhoef, T.; Dickie, C.; Ni, M.Z.; Huddy, J.R.; Soljak, M.; Hanna, G.B.; Majeed, A. Does use of point-of-care testing improve cost-effectiveness of the NHS Health Check programme in the primary care setting? A cost-minimisation analysis. BMJ Open 2017, 7, e015494. [CrossRef] [PubMed]

16. Oh, J.; Yun, K.; Hwang, J.-H.; Chae, J.-H. Classification of suicide attempts through a Machine learning algorithm Based on Multiple systemic Psychiatric scales. Front. Psychiatry 2017, 8, 192. [CrossRef] [PubMed]

17. Oh, J.; Yun, K.; Maoz, U.; Kim, T.-S.; Chae, J.-H. Identifying Depression in the National Health and Nutrition Examination Survey Data using a Deep Learning Algorithm. J. Affect. Disord. 2019. [CrossRef] [PubMed]

18. Kupke, I.R.; Zeugner, S.; Gottschalk, A.; Kather, B. Differences in lipid and lipoprotein concentrations of capillary and venous blood samples. Clin. Chim. Acta 1979, 97, 279-283. [CrossRef]

(C) 2019 by the authors. Licensee MDPI, Basel, Switzerland. This article is an open access article distributed under the terms and conditions of the Creative Commons Attribution (CC BY) license (http://creativecommons.org/licenses/by/4.0/). 